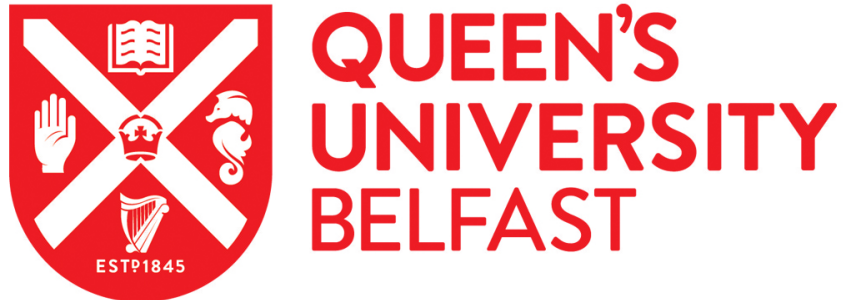

\section{The effect of choice on motivation for young children on the autism spectrum during discrete trial teaching}

Elliott, C., \& Dillenburger, K. (2014). The effect of choice on motivation for young children on the autism spectrum during discrete trial teaching. Journal of Research in Special Educational Needs.

https://doi.org/10.1111/1471-3802.12073

Published in:

Journal of Research in Special Educational Needs

Document Version:

Early version, also known as pre-print

Queen's University Belfast - Research Portal:

Link to publication record in Queen's University Belfast Research Portal

Publisher rights

This is a pre-print that was accepted for publication. The final publisher version can be found here:

http://onlinelibrary.wiley.com/doi/10.1111/1471-3802.12073/abstract

\section{General rights}

Copyright for the publications made accessible via the Queen's University Belfast Research Portal is retained by the author(s) and / or other copyright owners and it is a condition of accessing these publications that users recognise and abide by the legal requirements associated with these rights.

Take down policy

The Research Portal is Queen's institutional repository that provides access to Queen's research output. Every effort has been made to ensure that content in the Research Portal does not infringe any person's rights, or applicable UK laws. If you discover content in the Research Portal that you believe breaches copyright or violates any law, please contact openaccess@qub.ac.uk. 
The effect of choice on motivation for young children on the autism spectrum during Discrete Trial Teaching

Journal of Research in Special Educational Needs (2014)

\author{
Ceri Elliott \\ $\&$ \\ Karola Dillenburger \\ Centre for Behaviour Analysis \\ School of Education \\ Queen’s University Belfast \\ Belfast BT71HL \\ Northern Ireland
}

This research was conducted in part-fulfilment of the MScASD at Queen's

University Belfast by the first author under the supervision of the second author. Correspondence should be addressed to k.dillenburger@qub.ac.uk 
Abstract

Self-determination and decision-making are acknowledged internationally as key rights of persons with disabilities (UNCRPD, 2006) and should play an important role in the development of educational plans and procedures. Not only is the chance for individuals with developmental disabilities to select their own tasks, leisure activities, or reinforcers a valuable way of enhancing rights-based education and personal dignity, but choice-making opportunities may also function as a useful clinical or educational tool if they actually improve the efficacy of programmes aimed at the acquisition of socially relevant behaviours and life skills or the reduction of challenging behaviours (Lerman, Iwata, Rainville, et al., 1997).

The study reported here assessed whether or not choice affected effectiveness of an educational procedure for three children on the autism spectrum. Following a preference assessment, a number of discrete teaching trials were conducted with each child and, contingent upon targeted responses, either the child or the therapist selected one of three preferred reinforcer items. Reinforcer choice did not affect intervention effectiveness for two of the children, however performance and motivation improved for the third child. Results re-affirmed the importance of thorough preference assessments prior to intervention and showed that additional stimulus choice contingent on the target response may improve motivation and outcomes for some children.

Key words: Applied Behaviour Analysis, ABA, Autism, Discrete Trial Training, DTT, Choice, Reinforcer 


\section{The effect of choice on motivation for young children on the autism spectrum during Discrete Trial Teaching}

A wide range of interventions are available aiming to support individuals diagnosed with Autism Spectrum Disorders, from scientifically validated procedures to parent developed self-help treatments to apparently charlatan and fad treatments (Freeman, 2007). Interventions that have strong empirically sound research supporting their use as a medical and educational tool are based almost exclusively on the application of behaviour analytic principles (National Standards Project, 2009). One important such principle, used in procedures such as Discrete Trial Teaching (DTT), is operant conditioning. Operant conditioning describes the process by which behaviours are acquired, maintained or modified dependent on the antecedents in place prior to the response and the consequence that follows the behaviour. This principle can be used in a planned manner to teach new skills, such as in the case of DTT, a carefully planned shaping procedure that teaches new behaviours by successive approximation in discrete trials or 'learn-units' (Greer \& McDonough, 1999). In a meticulously planned setting and teaching sequence, each trial includes the presentation of an antecedent stimulus (A) that elicits a behavioural response (B) and is followed by the contingent delivery of a reinforcing stimulus (C). Each learn-unit represents a learning opportunity for the target behaviour and therefore during each treatment session, multiple learn-units/trials are presented.

The assessment and availability of effective reinforcers is key for education in general, and vital for effective DTT. Identification and selection of effective reinforcers are important pre-requisites and commonly a detailed preference assessment is conducted with individual learners to ensure that only preferred items are considered for use as reinforcers (Keenan, Kerr, \& Dillenburger, 2000). Not surprisingly, items or stimuli that function as effective reinforcers for one behaviour may not do so for another, because reinforcer effectiveness depends on a wide range of variables, including individual learning history, prevailing contingencies, and cultural contexts. Events or circumstances that alter reinforcer value and, consequently, alter behaviour are called 'motivation operations' (Michael, 1993). Motivation operations can 'establish' or 'abolish' reinforcer effectiveness. For example, stimuli to which the individual has limited access (a process called 'deprivation') are likely to become more effective than those that are familiar and always available (a process called 'satiation') (Lovaas, 2003). Limiting access to some highly preferred stimuli therefore can function as a motivation operation to increase the effectiveness of a reinforcer for a particular behaviour.

The question addressed in this paper is how choice influences reinforcer effectiveness. In other words, does choice affect the effectiveness of a reinforcer and therefore can choice usefully be considered a motivation operation?

There is much literature on reinforcer preference assessments and these have become routine part of behaviour analytic interventions (Kelly, Roscoe, Hanley, \& Schlichenmeyer, 2014; Weldy, Rapp, \& 
Capocasa, 2014). Yet to-date, the evidence related to choice per se and its influence on the reinforcing value of a stimulus has been thin and results have been mixed.

There is some early evidence that children with severe developmental disabilities, including autism, engage in more on-task behaviour and less inappropriate, disruptive, or social avoidance behaviour, when they are provided with opportunities to make choices about tasks or activities, as opposed to when the teacher selects the activity (Dyer, Dunlap, \& Winterling, 1990; Dunlap, dePerczel, Clarke, et al., 1994). More recently Koegel, Singh, and Koegel (2010), investigated the opportunity to choose in an educational environment and found that this decreased latency between antecedent and behaviour, i.e., engagement in academic task, improved the rate of performance and interest, and decreased disruptive behaviour in the classroom.

Tasky, Rudrud, Schulze, and Rapp. (2008) investigated the effects of choice on task engagement in three adults diagnosed with traumatic brain injury and found that permitting individuals to choose from a list of tasks increased on-task behaviour. The decreasing levels of on-task behaviour observed during the control phases suggested that the opportunity to choose the task rather than preference for or difficulty of the task produced these effects.

Although all of these studies have shown that offering individuals with disabilities the opportunity to make choices can have beneficial effects, they focus largely on the effects of choice of the task or activity, i.e., the antecedent of the target behaviour, rather than the possibility of choice constituting a motivation operation.

Very few studies have explored the effect of choice of reinforcers, despite the fact that Fenerty and Tiger (2010) established that typically developing pre-schoolers preferred reinforcer choice to task choice (cf. Brighman \& Sherman, 1973). Early studies such as Pace, Ivancic, Edwards, et al. (1985) and Mason, McGee, Farmer-Dougan, and Risley (1989) found choice via a reinforcer assessment resulted in lower rates of maladaptive behaviour, however, they offered choice of reinforcers prior to the teaching trial and therefore results say more about the effectiveness of preference assessment than about reinforcer choice. Smith, Iwata, and Shore (1995) also found that choice-making opportunities prior to the trial did not influence the reinforcing value of a stimulus.

These results suggest that it may be access to preferred stimuli, rather than the opportunity to make additional choices that influenced the reinforcing value of a stimulus. Although, Waldron-Soler, Martella, Marchand-Martella, and Ebey (2000) used less preferred reinforcers and also found no differential effect between choice and no-choice conditions.

While choice appears to increase the reinforcing value of a stimulus for some individuals this is not the case for others (Bambara, Ager and Koger, 1994; Lerman et al., 1997; Vaughan \& Horner, 1997). The question remains if choice produces effects on responding, even if both the choice and no-choice conditions produce the same consequence (Catania, 1980). It seems that when concurrent operant 
schedules have been used in laboratory settings, a clear preference for choice exists (Graff \& Libby, 1999; Geckler Libby, Graff, \& Ahearn 2000). Fisher, Thompson, Piazza, et al. (1997) concluded that providing choices 'adds to the reinforcement value of the chosen stimuli and thus may have the potential to improve the effectiveness of behavioural programmes' (p.433). Tiger, Hanley and Hernandez (2006) confirmed that children preferred the choice condition, even if it was attached to more difficult tasks.

These studies appear to strongly suggest that the opportunity to choose is more than simply access to more highly preferred stimuli, i.e., the opportunity to choose may have reinforcer altering function. However, previous findings may be explained by the delay between the opportunity to make a choice and receiving the reinforcing stimuli, i.e., the reinforcer choice was offered prior to engaging in the task. This delay may negate the motivational effect of choice. The question remains, whether or not choice influences the value of a reinforcing stimulus. The effects of choice per se on responding may be apparent when the trial is framed as 'choice condition', and choice making is available only following the response, i.e., immediately prior to receiving the chosen reinforcer.

For the present study, the implications of this state of play are twofold. First, the greater the value of a reinforcing stimulus, the more effectively new skills are acquired and second, despite a large body of evidence supporting DTT as an effective teaching tool in the education of children diagnosed with Autistic Spectrum Disorders, this method has been criticised for being too teacher-driven. DTT is a tightly prescribed procedure. Target behaviours are either based on parent-professional agreement or on developmental or academic curricula; reinforcers are identified on the basis of individual child-led preference assessments. Apart from this, traditionally DTT does not include much by the way of choice for the child and strict treatment fidelity, i.e., adherence to protocols, is recommended.

Researchers such as Greenspan (1992) and Smith (2001) have expressed concern that the teacher directed nature of DTT introduced a bias that emphasises skill building at the neglect of a child's social and emotional needs. From a human rights perspective, traditional DTTs offer little in the way of self-determination (Schreibman, 2007). If choice were to enhance reinforcer effectiveness, practitioners using DTT could offer children the opportunity for self-determination whilst maintaining treatment fidelity. The present study investigated if the introduction of reinforcer choice in DTT, i.e., framing the DTT in a choice condition with choice available immediately prior to reinforcer delivery, would have a motivating effect for learning. 


\section{METHODOLOGY}

\section{PARTICIPANTS AND SETTING}

Three boys with a diagnosis of ASD who were enrolled in home-based early intensive behavioural intervention (EIBI) programmes took part in the study. Apart from EIBI, the children also attended playschool. Jo was 4 years and 3 months old at the time of the study and received twenty-five hours of one-to-one EIBI (a combination of DTT and Natural Environment training, NET) in the living room of his home. Will was 4 years and 6 months old and received thirty hours of EIBI a week, in a room in his home that was specially allocated to this purpose. Sam was 4 years and 6 months old at the time of the study and received twenty hours of EIBI in his bedroom.

All three children were able to communicate their needs and preferences vocally. Jo and Will communicated their preferences using short sentences, for example 'I want to play....' or 'work for....'; Sam's communication level was similar to his peers but he used more complex sentence structure, e.g., 'After we.... I think maybe I would like to play with the....'.

During casual observations of typical therapy session, Jo seemed relatively socially aware and responsive. He appeared to enjoy the social interaction with the therapist ( $1^{\text {st }}$ author). His skill acquisition rate was slower than the other boys, but this was more due to lower ability than his cooperation in the sessions. Will was less socially aware and seemed less motivated by social interaction. However, at times he showed interest in access to a small toy train, in the shape of the cartoon character of Thomas the Tank Engine.

Sam had a very high skill acquisition rate although he was less socially aware than the other boys. Sam preferred to play alone at times, while at other times he was very engaging, especially when engaging in activities he enjoyed, when he became very vocal and engaged in joint attention.

All sessions were conducted in the room in which their usual EIBI took place. For the purposes of therapy each room was arranged in a very similar manner. In each setting, there was a small table, with two chairs on opposite sides, one for the child and one the therapist. There was an open mat area for playing games on the floor.

Sessions comprised of short bursts of DTTs at the table lasting a maximum of five minutes each and after a maximum of three DTTs the child and the therapist moved to the mat for a less structured play based activity for a period of about five minutes. All the materials, games, and toys necessary to implement the sessions were prepared in advance and stored in a box beside the therapist's chair and included a range of small coloured picture templates depicting a range of people (who), objects (what) and places (where). Potentially motivating items, such as toys and games, puzzles, kerplonk, donkey, a box of farm animals, a garage and toy cars, were arranged around the mat making it easy for the child or therapist to choose one. 


\section{TARGET BEHAVIOURS AND RESEARCH TOOLS}

The target behaviour was 'accurate discrimination between $\mathrm{WH}$ - questions', i.e., $\mathrm{WH}$-discrimination:

- Who, referring to a person;

- What, referring to an action or an object; or

- Where, referring to a place.

Following a preference assessment (described below) potential reinforcer items were identified and available as follows:

- For Jo, a toy oil dripper, a singing book, a wind up ladybird, a wind up frog, a spinning top, a flick book;

- For Will, a Thomas the Tank Engine book, a small Thomas train, a large Thomas train in a circular track, a picture of all the trains in the Thomas series, a head scratcher, a vibrating dog massager;

- For Sam, a toy helicopter, a small magnetic spaceman, a giggle stick, five plastic haahoos, a Night Garden spinning gazebo, a light up spinner.

\section{PROCEDURE}

Prior to the start of the study, parent and therapist feedback was used to identify a pool of twelve potentially reinforcing stimuli for each child. Using a paired stimuli choice assessment in which pairs of stimuli were held up and the child asked which they would like to play with, the selection was narrowed to six highly preferred items for each child. Fisher, Thompson, Piazza and Gotjen (1997) found that offering children a choice of pairs of stimuli and allowing them access only to the first stimuli they had chosen, established a highly accurate assessment of the child's preference (preferred reinforcer items for each child were listed under Research Tools).

At the start of each session an additional very brief preference assessment was carried out to identify the three stimuli that were the most highly preferred items for that particular session. Each of the items was held up in pairs and the child was asked which they would prefer to play with. In order to check for accuracy, the three items that were verbally identified as preferred items were then held up together with another one of the original six and the three items that the child identified as most preferred were used in the session that followed.

During the three-hour EIBI session that followed immediately after the preference assessment, a fixed ratio one schedule (FR1) was in place for all skills acquisition phases, i.e., every correct response was followed with immediate reinforcer delivery. In the skills maintenance phase, this reinforcement schedule was thinned to a variable ratio three schedule (VR3), i.e., average of every third target response was reinforced.

For the matching phase, the child sat at the table and three picture templates containing examples of people (who), objects (what) and places (where) were placed on the table in front of the child. A 
picture of a person, an object or a place was given to the child with the verbal instruction "put with who/where/what'. The target response was to place this picture on top of the corresponding template.

During the receptive phase three pictures, a person, an object, a place, where placed on the table in front of the child. The instruction was 'give me who/where/what'. The target response was to pick up the corresponding picture and hand it to the therapist.

The first two instances of instruction for each new target response were fully prompted, i.e., the child was immediately physically prompted to engage the correct response without the opportunity to respond independently and reinforcers were delivered immediately following the prompted correct response. From the third instruction onwards the child was given the opportunity to respond independently. If the child responded correctly they immediately received a reinforcer. If they responded incorrectly they were asked to try again. The instruction was repeated and a full physical prompt was used to ensure the correct response (errorless learning); verbal praise was used but no tangible reinforcers were made available for fully prompted responses. The instruction was then repeated giving the child another opportunity to respond independently. If the child responded with the correct target behaviour verbal praise and a tangible reinforcer were delivered immediately. If the child responded incorrectly they were asked to try again, the instruction was repeated and full prompting was used for the correct response. Verbal praise was used without additional reinforcer items and the instruction was not repeated until the next session.

In the next session the instruction was repeated and in the first instance full physical prompting was used for the correct response, i.e., the child did not have the opportunity to respond independently. Verbal praise and tangible reinforcers were delivered. The instruction was then repeated and the child was given the opportunity to respond independently, with the same consequences as before. If on any instance of instruction the child did not respond within three seconds, this was considered a nonresponse and treated in the same manner as an incorrect response. Data were taken on each response opportunity. A maximum of ten trials per session were conducted.

To measure the effect of reinforcement on compliance and motivation throughout the session data were also taken on the instruction 'come sit'. When, for example after a break, the instruction was used 'come sit' the target response was that the child would stop the break-time activity and come to the table and sit down on their chair. Data were taken on compliance, speed, and interfering behaviours. If the child took longer than 3 seconds to begin to respond, the response was tallied as slow response but considered correct and verbal praise and tangible reinforcers were provided. If the child took longer than 5 seconds to respond this was considered a non-response. The child was asked to try again. The instruction 'come sit' was restated and when the child came to the table and sat on the chair, verbal praise was given but no other reinforcers were delivered. The few occasions when a child responded immediately and moved at a very fast walk or even a run to the table, were considered a fast response. Data were taken also if any behaviour other than the target behaviour 
occurred. If the child engaged in any behaviour other than the target behaviour from the time the instruction 'come sit' was issued to the time the child sat in the chair, this was recorded in field-notes.

Two three-hour intervention periods per week were conducted with each child; each period consisted of three forty-five minute therapy sessions with fifteen-minute breaks between sessions. The intervention periods reported in the present study were incorporated into the current home-based intervention programmes; no additional time was required. The wh-discrimination was targeted once per forty-five minute therapy session, totalling three times per three-hour intervention period. Each session consisted of a maximum of ten discrete trials. The instruction 'come sit' occurred each time the child needed to return to the table after a break, and were tallied for each therapy session totalling three per three hour intervention period throughout the three hour period.

\section{EXPERIMENTAL DESIGN}

No-choice condition: for every accurate response for which a reinforcer was to be delivered, the experimenter chose one of the three highly preferred items and allowed the child to play with the chosen toy for a short period of time (approx. 30 seconds).

Choice condition: for every target response for which a reinforcer was to be delivered the experimenter showed the three items available and the child verbally requested the item they chose as reinforcer on this occasion. The child was then allowed to play with the chosen toy for a short period of time (approx. 30 seconds).

In order not to distort results by adding extra therapy time, the research was conducted as part of the structured home-based EIBI programme. An alternating treatment research design was used in order to compare choice vs no-choice conditions. Given that no-choice conditions had been used in all EIBI programmes prior to this study (i.e, no-choice condition was considered 'treatment as usual'), this condition also supplied baseline data. The no-choice condition was applied to two sessions per week for two weeks, then the choice condition was applied for two therapy sessions per week for two weeks. Subsequently, there was a return to the no-choice condition for two sessions for one week and finally, a return to the choice condition for two sessions for one week.

\section{RESULTS}

Figure 1 shows the percentage of correct responses during the acquisition of Wh question discrimination for all three of the children. Whenever a new item was introduced, full prompting was used for the first two trials. The percentage of non-responses per session was included to give a fuller picture.

\section{Insert Figure 1}


Jo and Will showed similar levels of skill acquisition in both the no-choice and the choice conditions. For Jo there were no instances of non-responding, while for Will there were similarly low levels of non-responding across both conditions.

Sam's data showed a small increase in skill acquisition in the choice phases when compared with the no-choice phases. There were also considerably higher levels of non-responding during the no-choice phases with only one instance of non-responding during the choice phases in Session 25. Field notes evidenced that on a number of occasions during the first no-choice phase Sam requested a choice. For example in Session 11, when the therapist handed Sam the In the Night Garden book as reinforcer, Sam responded by saying 'No, maybe I would like to play with the Haahoos now'. He did not respond to the next instance of instruction 'put with Where'. In Session 14, the therapist handed Sam the spaceman as reinforcer. When denied the opportunity to choose, he handed the spaceman back to the therapist saying 'No, I don't want to play with the spaceman.' Again, on the next instance of instruction he became unresponsive and had to be physically prompted to 'put with Where'.

In the second no-choice phase Sam attempted to negotiate less often but during Session 33, when the therapist handed him the HaaHoos he requested to play with a fire-engine which was not one of his highly preferred items and anecdotally not something he generally liked to play with.

Table 2 shows percentage of correct responding and non-responding to the instruction to 'come sit' back at the table for each teaching period during no-choice and choice conditions for Jo, Will and Sam.

\section{Insert Figure 2}

The 'come sit' instruction was given at the beginning of each new teaching session, in other words, after each break from the table, the child was instructed to come and sit back at the table. For Jo and Will, there was no significant difference in responding to the 'come sit' instruction during either of the conditions. Both boys responded well to the instruction with a relatively low level of non-compliance.

For Sam, however there was a marked difference between the two conditions. In the no-choice condition he showed considerable levels of non-compliance to the instruction to come and sit at the table after each mat based activity, in fact, at some occasions he actually shouted 'no' or 'I won't'. At the beginning of the last no-choice session when Sam was asked to 'come sit' he threw himself on the floor and shouted 'no, no, never ever'.

In contrast, in the choice condition he used sentences of a level of sophistication that had not been observed before. For example on his way to the table, he said 'Can I chose the one I want? Ok, well I think I would like to play with the..... At the beginning of the subsequent no-choice condition he used quite elaborate negotiation skills to get the therapist to change her mind, saying 'But Ceri, I think 
maybe I would like to choose'. When he was told that this was a no-choice condition he became nonresponsive.

In order to have further measure of motivation, latency between instruction to 'come sit' and accurate child response was measured; short latency, i.e., fast responding (less than two seconds) was considered highly motivated and longer latency, i.e., slow response (within five seconds) was considered lack of motivation. Figure 3 shows that Jo generally responded within relatively short response times.

\section{Insert Figure 3}

Will responded slowly (long latency) most of the time (Table 4). There was little difference in the choice and no-choice conditions.

\section{Insert Figure 4}

Sam responded slowly during no-choice conditions. In fact, there was only one instance of fast responding during the both no-choice phases. However, latency increased considerably during choice conditions (Table 5). On a number of occasions he requested a specific reinforcer item of choice while moving rapidly to the table, saying for example 'I think maybe I would like to play with the helicopter' or 'No, I don't think I want the helicopter, maybe I could play with the fireman instead?'

\section{Insert Figure 5}

\section{Discussion}

The effect of choice on reinforcer effectiveness and motivation during DTT (who, what, where discriminations) was assessed for three children with a diagnosis of Autism Spectrum Disorder. Preferred potential reinforcer items were identified in a paired stimuli choice preference assessment prior to the intervention. In the non-choice condition, the therapist provided one of the three preferred items contingent on accurate responding, in the choice condition the child chose one of the three preferred items immediately after the response, i.e., just prior to reinforce delivery. Choice did not have an effect on reinforcer effectiveness or motivation for two of the children (Jo and Will); however, for the third child (Sam) there was an increase in accurate responding and motivation in the choice condition, as well as the emergence of novel and advanced behavioural variability.

Most of these findings concur with the existing literature (e.g., Bambara, Ager \& Koger, 1994; Fenerty \& Tiger, 2010; Tasky et al., 2008; Vaughn \& Horner, 1997) where choice effects occur with some but 
not all participants. In our study, choice influenced the value of a reinforcer for one child, but not the other two. Whilst Jo's data indicated slightly higher levels of responding than Will's, for both children, responding remained consistent over all phases of the study. For Sam, however, choice made a big difference.

Choice can be used in one of two ways; as an efficient tool for identifying individual preferences or as choice 'per se' (Dyer, Dunlap, \& Winterling, 1990). There is extensive literature regarding the use of choice to identify individual preferences in reinforcer assessments. The question addressed by the present research related to the effect of choice per se.

We found that for some children choice per se appeared to function as a motivation operation (Michael, 1982). Motivation operations alter ('establish' or 'abolish') the effectiveness of a reinforcer and lead to new or changed behaviours. For Sam, the inclusion of choice into the DTT clearly seemed to function as an establishing operation. For him, choice increased both skill acquisition and motivation to participate and facilitated the emergence of complex sophisticated novel behaviours. Choice seemed to become increasingly important for Sam; in fact, on one occasion during a nochoice condition he verbally requested a reinforcer that had been considered only moderately preferred during pervious preference assessments.

The influence of choice per se on motivation was apparent in Sam's quickly coming to the table during the choice condition and the markedly slower response to the 'come sit' instruction during the nochoice condition. It is also interesting to note that this reluctance to participate increased steadily during the no-choice sessions. As such, the opportunity to choose in one condition had an adverse effect in the no-choice condition. Future studies should consider the potential of this 'behavioural contrast effect' (Catania, 1992) when introducing choice-making contingencies.

In most existing studies, choice is offered prior to presentation of the antecedent stimulus, but following a preference assessment, i.e., the child chooses which of the preferred items they wanted to work for during a specific trial, prior to the beginning of the trial (Dyer, Dunlap \& Winterling, 1990; Fisher et al., 1997; Geckler et al., 2000). This sequence can be represented in the following formula (where $\mathrm{R}^{\mathrm{c}}$ stands for reinforcer choice and $\mathrm{A}-\mathrm{B}-\mathrm{C}$ stand for one learn unit/three term contingency in a DTT).

$R^{c}---A-B-C$

Mason et al. (1989), Tasky et al. (2008), and others found that once a pool of highly preferred reinforcers was established the opportunity for further choice prior to the trial did not improve task performance.

We included choice making after the response, i.e., immediately prior to reinforcer delivery. This response contingent choice condition is represented in the following formula. 


\section{$A-B-\left(R^{c}\right) C$}

Lerman et al. (1997) thought that response contingent access to choice did not increase response rates when compared to the no-choice condition. Yet, we found that initially response contingent choice seemed to increase reinforcer effectiveness for Sam, in fact in some instances Sam requested choice before he was even seated for the trial. This may indicate that the timing of choice making is important. Further research would need to explore the idea of choice timing and response contingent choice making experimentally.

Alternatively, choice per se could be considered a motivation operation that 'frames' the entire interactional sequence during a choice condition. This would be represented as follows:

$R^{c}(A-B-C)$

For Sam, choice seems to function as motivation operation as evidenced in increased reinforcer value, even of previously non-preferred items. In addition, the emergence of novel vocal behaviour at a level of sophistication not previously observed was intriguing. Further research should explore the impact of choice per se on behavioural variability, especially in the context of generating behavioural cusps (Rosales-Ruiz \& Baer, 1997). This could have important treatment implications, for example in pivotal response training (Koegel, Koegel, Vernon, \& Brookman, 2009).

On a practical note the introduction of choice could mitigate against satiation effects and thus could render daily preference assessments unnecessary. Choice itself could become an activity reinforcer as represented in the following formula:

\section{$A-B-R^{c}$}

For example, Dyer, Dunlap, G., and Winterling (1990) found that levels of aggressive behaviour increased in the second no-choice condition when compared to the first. In our study, however Sam displayed lower levels of noncompliant behaviour during the second no-choice condition. As such, maybe choice per se functioned to reinforce compliance.

Given that choice is such an important human right, providing for enhanced personal autonomy and quality of life (Cannella, O'Reilly, \& Lancioni, 2005), the question remains why choice was not 'working' for Jo and Will. How can we make choice a more important factor in the life of children like these? It is possible that for some of the children choice would be preferred, but due to communication difficulties they are not able to express their choices. If this were the case, it is important to find ways to enhance communication skills and thus choice making opportunities for these children. 
For others, the effect of choice outside of preference assessments needs to be investigated further so that we may know more about the conditions under which choice making enhances performance. We should investigate the impact of developmental levels or intellectual ability on choice making. In cases where the opportunity to choose per se has little influence on behaviour, individual preference assessments remain important, however, the main focus should be to teaching individuals with developmental disabilities to effectively indicate their choices.

Alternatively, for those individuals for whom choice functions as motivation operation, choice-making opportunities should routinely be included in structured interventions. The fact that reinforcer choice increased the reinforcing effects of even of highly preferred stimuli for Sam has implications for those working with children on the autistic spectrum. The key to all good early intensive behavioural intervention is individualising the programme to fit each child's unique pattern of existing developmental skills as well as their developmental skills deficits and excesses (Green, 2001). It is important therefore that practitioners consider choice as an important factor in programme design.

In sum, according choice to individuals on the autism spectrum is not only important from a human rights perspective, it can have an important therapeutic effect due to its motivational function.

\section{References}

Bambara, L, Ager, C and Koger, F. (1994) The effects of choice and task preference on the work performance of adults with severe disabilities. Journal of Applied Behaviour Analysis, 27, 555-556

Brigham, T., \& Sherman, J. (1973). Effects of choice and immediacy of reinforcement on single response and switching behaviour of children. Journal of Applied Behaviour Analysis, 19, 425-435

Cannella, H.I, O'Reilly, M.F and Lancioni, G.E. (2005). Choice and preference assessment research with people with severe to profound developmental disabilities: A review of the literature. Research in Developmental Disabilities, 26, 1-15.

Catania, A. C. (1980) Freedom of choice: A behavioural Analysis. The Psychology of Learning and Motivation, 14, 97-145

Catania, A. C. (1992) Learning. Englewood Cliffs NJ: Prentice-Hall

Dunlap, G., dePerczel, M., Clarke, S., Wilson, D., Wright, S., White, R., et al. (1994). Choice making to promote adaptive behavior for students with emotional and behavioral challenges. Journal of Applied Behavior Analysis, 27, 505-518.

Dyer, K., Dunlap, G., \& Winterling, V. (1990). Effects of choice making on the serious problem behaviours of students with severe handicaps. Journal of Applied Behaviour Analysis, 23, 515-524. 
Fenerty, K.A. \& Tiger, J.H. (2010). Determining preschoolers' preferences for choice-making opportunities: Choice of task versus choice of consequence. Journal of Applied Behavior Analysis, 43, 503-507.

Fisher, W, Thompson, R, Piazza, C, Crosland, K and Gotjen, D. (1997) On the relative reinforcing effects of choice and differential consequences. Journal of Applied Behaviour Analysis, 30, 423-438

Freeman, S. K. (2007). The complete guide to autism treatments. A parent's handbook: Make sure your child gets what works. Lynden, WA: SKF Books.

Geckler, A, Libby, M, Graff, R., \& Ahearn, W. (2000). Effects of reinforcer choice measured in singleoperant and concurrent-schedule procedures. Journal of Applied Behaviour Analysis, 33, 347-351.

Graff, R and Libby, M. (1999) A comparison of pre-session and within-session reinforcement choice. Journal of Applied Behaviour Analysis, 32, 161-173

Greer, R.D and McDonough, S.H. (1999). Is the learn unit a fundamental measure of pedagogy? The Behavior Analyst, 22, 5-16.

Green, G. (2001). Behaviour analytic instruction for learners with autism: Advances in stimulus control technology. Focus on Autism and Other Developmental Disabilities, 16 (2), 72-85

Keenan, M., Kerr, K. P., \& Dillenburger, K. (2000) (Eds). Parents' Education as Autism Therapists. London: Jessica Kingsley Publishers

Kelly, M.A., Roscoe, E.M., Hanley, G.P., \& Schlichenmeyer, K. (2014). Evaluation of assessment methods for identifying social reinforcers. Journal of Applied Behavior Analysis, 47, 113-135.

Koegel, Koegel, Vernon, \& Brookman (2009). Empirically supported Pivotal Response Treatment for Autism. In Weisz and Kazdin (2009). Evidence-based psychotherapies for children and adolescents. New York: Guilford Press.

Koegel, L, Singh, A., \& Koegel, R. (2010). Improving motivation for academics in children with autism. Journal of Autism and Developmental Disorders, 40, 1057-1066

Lerman, D, Iwata, B, Rainville, B, Adelinis, J, Crosland, K and Kogan, J. (1997). Effects of reinforcement on choice on task responding in individuals with developmental disabilities. Journal of Applied Behaviour Analysis, 30, 411-422

Lovaas, O.I. (2003) Teaching Individuals with Developmental Delays: Basic Intervention Techniques. Austin, Texas: PRO-ED Inc. 
Mason, S, McGee, G, Farmer-Dougan, V and Risley, T. (1989) A practical strategy for on-going reinforce assessment. Journal of Applied Behaviour Analysis, 30, 171-179

Michael, J. (1982) Distinguishing between discriminative and motivational functions of stimuli. Journal of the Experimental Analysis of Behavior. 37. 149-155.

Michael, J. (1993) Establishing operations. The Behavior Analyst, 16, 191-206.I cannot find in the text

National Standards Project. (2009). Addressing the need for evidence-based practice guidelines for autism spectrum disorders. Massachusetts: National Autism Centre

Pace, G, Ivancic, M, Edwards, G, Iwata, B and Page, T. (1995) Assessment of stimulus preference and reinforcer value with profoundly retarded individuals. Journal of Applied Behaivour Analysis, 18, 249-255

Rosales-Ruiz, J. \& Baer, D.M. (1997) Behavioral cusps: a developmental and pragmatic concept for behavior analysis. Journal of Applied Behavior Analysis, 30, 533-544

Schreibman, L. (2007) The science and fiction of Autism. Harvard University Press.

Smith, R, Iwata, B and Shore, B. (1995) Effects of subject versus experimenter selected reinforcers on the behaviour of individuals with profound mental disabilities. Journal of Applied Behaviour Analysis, 28, 61-71.

Tasky, K.K., Rudrud, E.H., Schulze, K.A., \& Rapp, J.T. (2008). Using choice to increase on-task behavior in individuals with traumatic brain injury. Journal of Applied Behavior Analysis, 41 Pages: 261-265.

Tiger, J.H., Hanley, G.P., \& Hernandez, E. (2006). An evaluation of the value of choice with preschool children. Journal of Applied Behavior Analysis, 39, 1-16.

United Nations Convention on the Rights of Persons with Disabilities (UNCRPD; 2006). Strasbourg: Assembly of European Regions. Retrieved from the Web 06/23/2011. www.un.org/esa/socdev/enable/rights/convtexte.htm.

Vaughan, B. \& Horner, R. (1997). Identifying instructional tasks that occasion problem behaviours and assessing the effects of student versus teacher choice among these tasks. Journal of Applied Behaviour Analysis, 30, 299-312. 
Waldron-Soler, K.M., Martella, R.C., Marchand-Martella, N.E., \& Ebey, T.L. (2000). Effects of choice of stimuli as reinforcement for task responding in preschoolers with and without developmental disabilities. Journal of Applied Behavior Analysis, 33, 93-96.

Weldy, C.R., Rapp, J.T., \& Capocasa, K. (2014). Training staff to implement brief stimulus preference assessments. Journal Of Applied Behavior Analysis, 47, 214-218. 

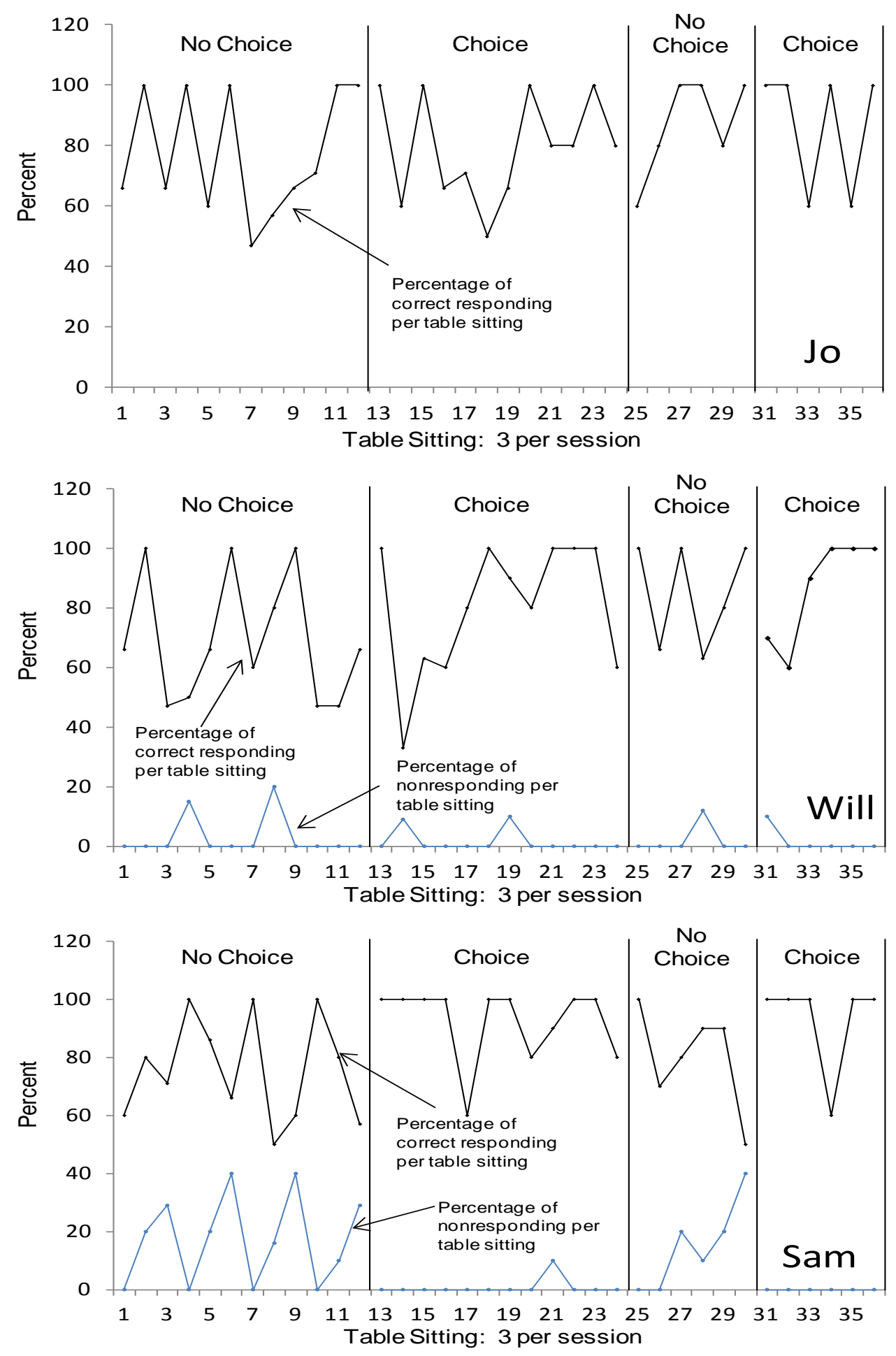

Figure 1: Percentage of correct responding and non-responding during the WH-Question discrimination skill acquisition phase for Jo, Will and Sam 

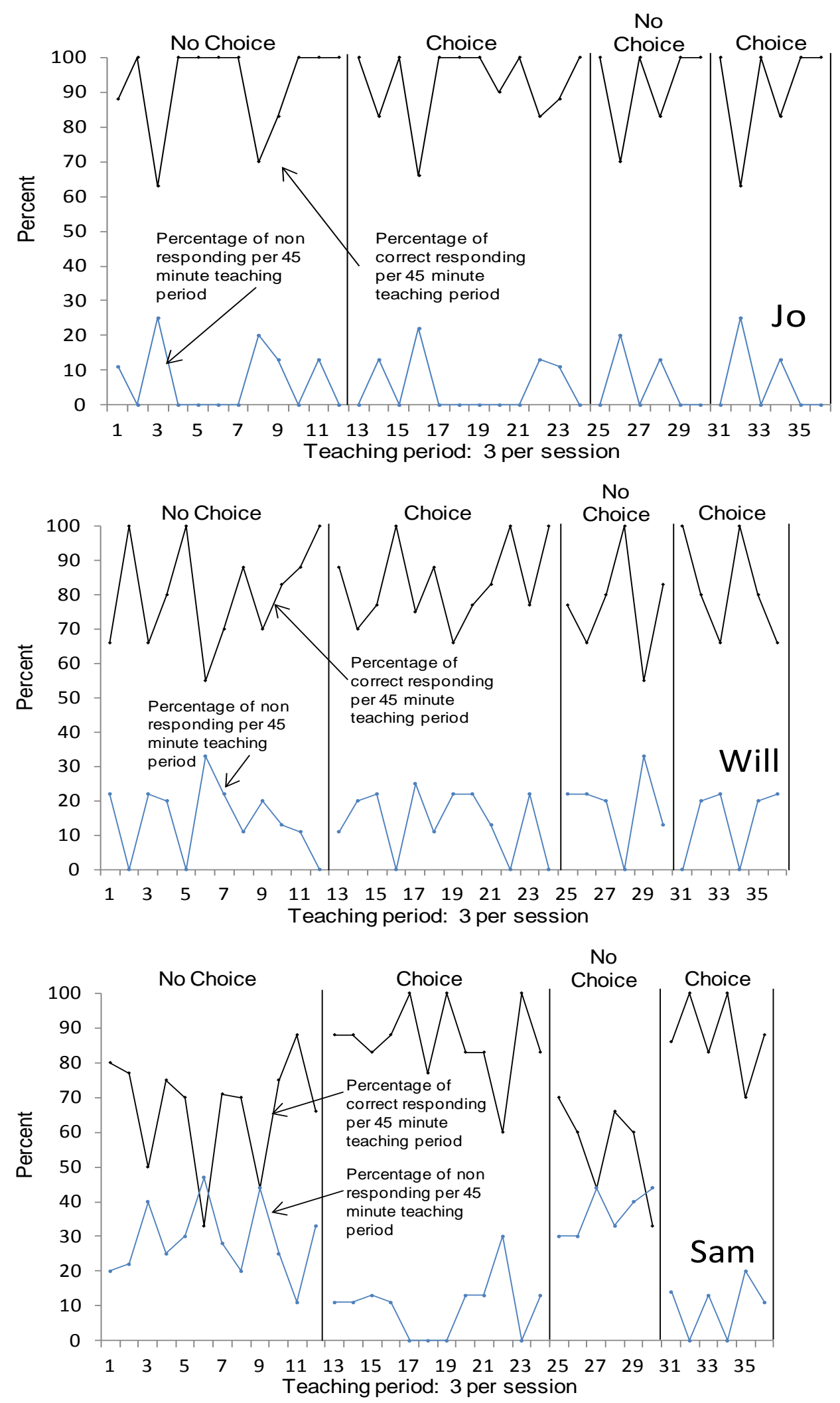

Figure 2: Percentage of correct responding and non-responding, to the instruction 'come sit' back at the table after a break during no-choice and choice conditions for Jo, Will and Sam 

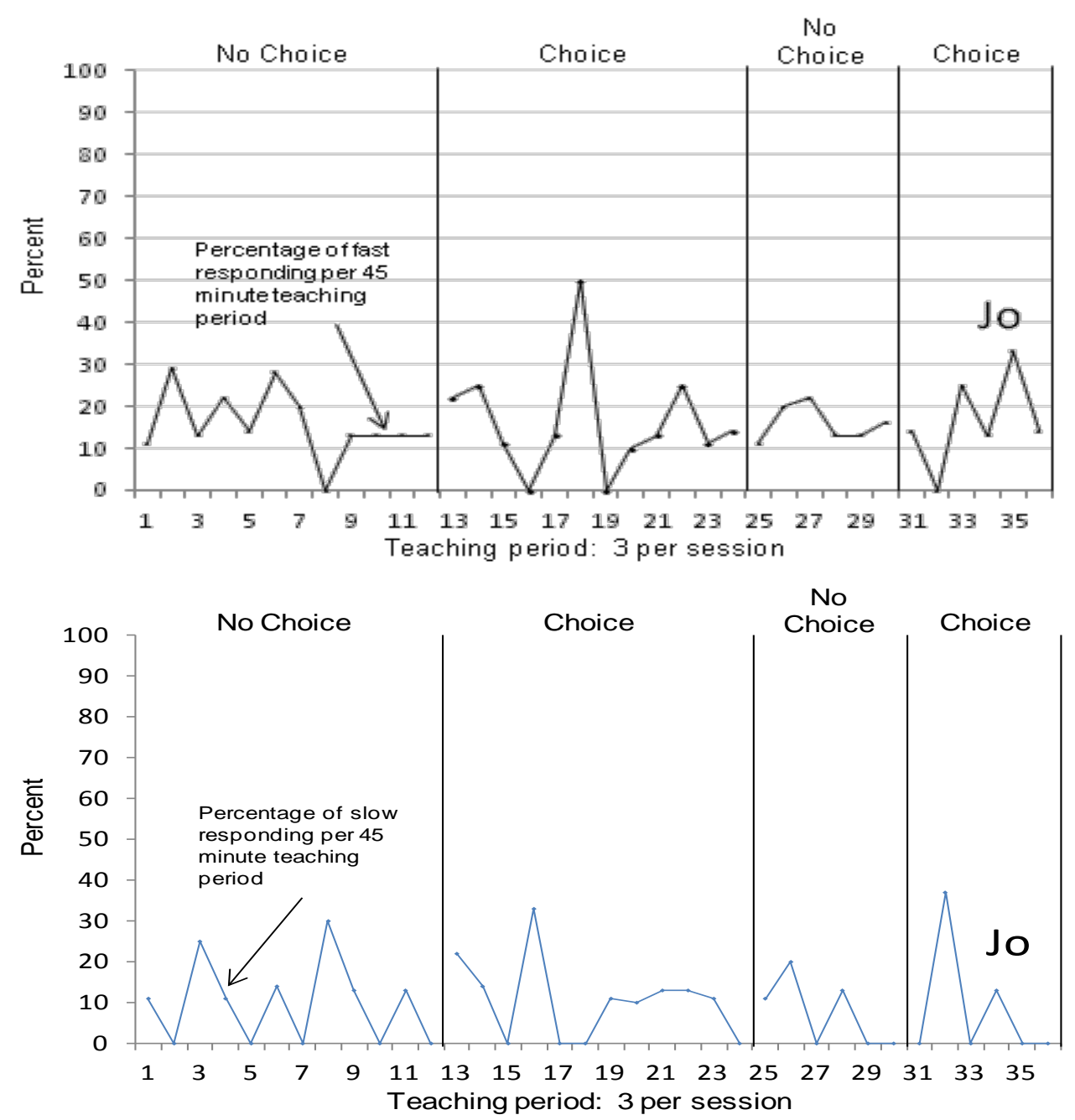

Figure 3: Response latency to the instruction 'come sit' for Jo across choice and no-choice conditions 

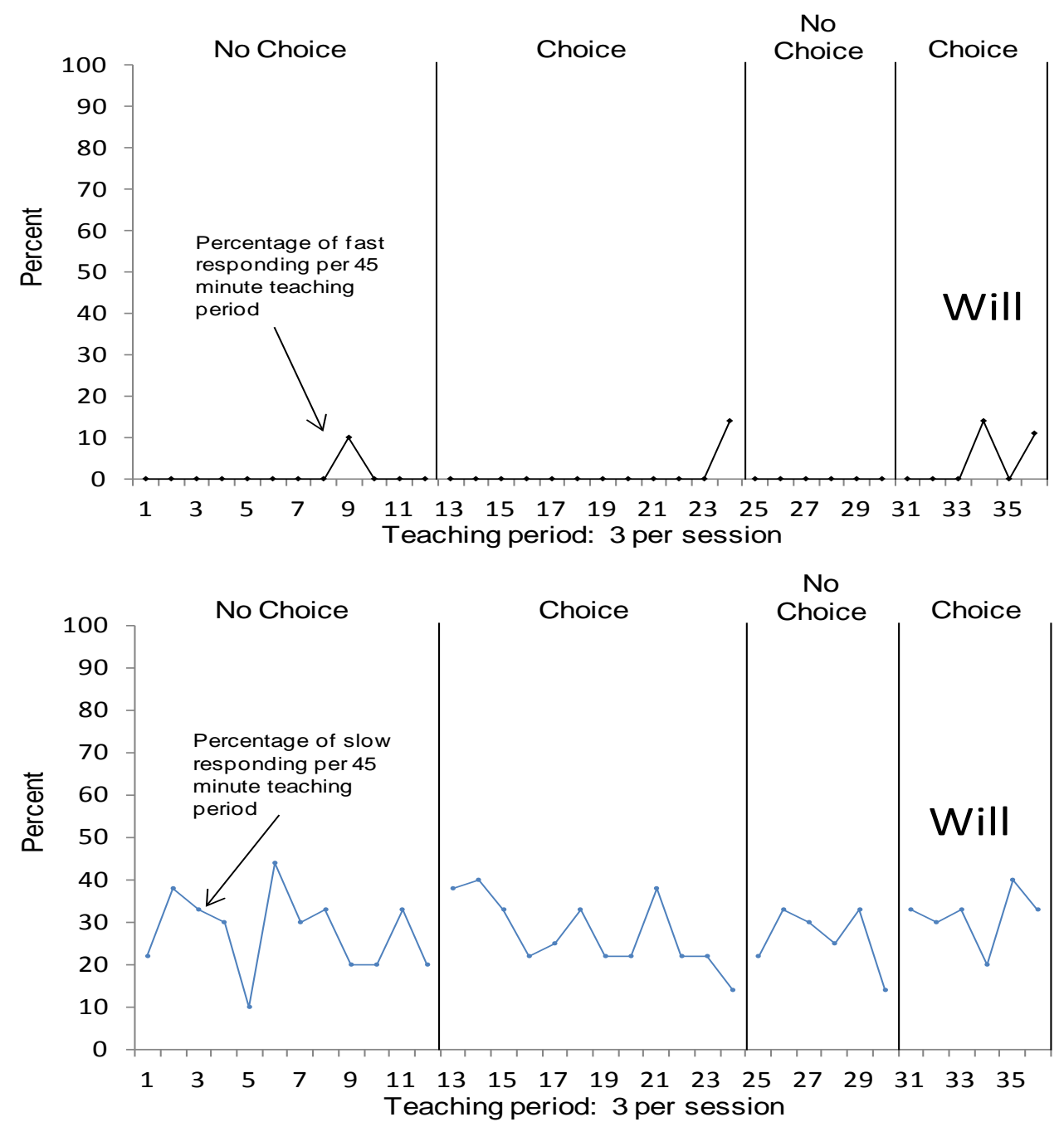

Figure 4: Response latency to the instruction 'come sit' for Will across choice and no-choice conditions 

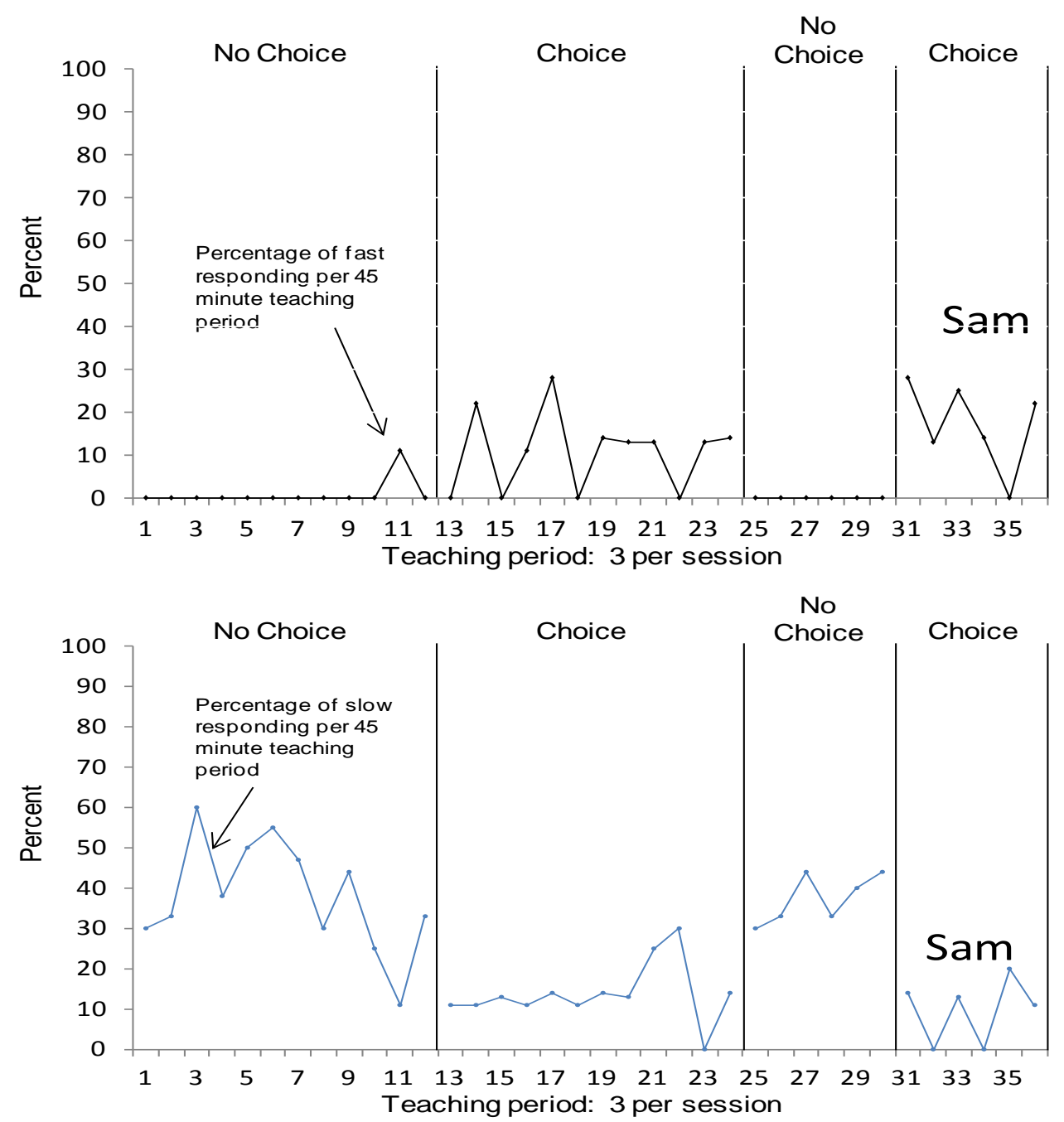

Figure 5: Response latency to the instruction 'come sit' for Sam across choice and no-choice condtions 